Ambiente \& Água - An Interdisciplinary Journal of Applied Science
ISSN 1980-993X - doi:10.4136/1980-993X
www.ambi-agua.net
E-mail: ambi.agua@gmail.com

\title{
Avaliação da adsorção de Fenol e Bisfenol A em carvões ativados comerciais de diferentes matrizes carbonáceas
}

\author{
doi:10.4136/ambi-agua.1698 \\ Received: 07 Jul. 2015; Accepted: 30 Sep. 2015 \\ Carla Rênes de Alencar Machado ${ }^{1 *}$; Enrico Mendes Saggioro ${ }^{2}$; \\ Yuri Gomes Leite e Silva ${ }^{1}$; Luiza Penna dos Santos Pereira ${ }^{1}$; \\ Juacyara Carbonelli Campos ${ }^{1}$ \\ ${ }^{1}$ Universidade Federal do Rio de Janeiro (UFRJ), Rio de Janeiro, RJ, Brasil \\ Programa de Pós-Graduação em Tecnologia de Processos Químicos e Bioquímicos \\ ${ }^{2}$ Fundação Oswaldo Cruz (Fiocruz), Escola Nacional de Saúde Pública, Rio de Janeiro, RJ, Brasil \\ *Autor correspondente: e-mail: carla.alencarmachado@gmail.com, \\ enrico.saggioro@ensp.fiocruz.br,yuri.go@hotmail.com,pereira.luiza@gmail.com, \\ juacyara@eq.ufrj.br
}

\section{RESUMO}

A remoção de compostos orgânicos tóxicos e micropoluentes orgânicos, provenientes de efluentes industriais, é uma crescente preocupação a fim de aumentar a qualidade da água para reúso. Para alcançar tal qualidade, alguns tratamentos têm se mostrado eficientes, tais como a adsorção em carvão ativado. Assim, o presente estudo avaliou a adsorção de fenol e bisfenol A (BPA) em carvões ativados comerciais de diferentes matrizes carbonáceas: betuminosa (CB) e vegetal (CV). Os carvões foram caracterizados por microscopia eletrônica de varredura (MEV) acoplada ao espectro de energia dispersiva (EDS), infravermelho (FTIR) e área superficial BET (Brunauer, Emmett, Teller). Foram realizados ensaios para definição de tempo de equilíbrio e ensaios para ajuste de isotermas de adsorção (Freundlich e Langmuir). A adsorção de fenol pelos dois tipos de carvões mostrou-se favorável, com remoção de $96 \%$ para o carvão CB e $91 \%$ para o carvão CV. No entanto, a adsorção de bisfenol A foi eficiente apenas para o carvão $\mathrm{CB}$, com eficiências de remoção em torno de $90 \%$ contra $20 \%$ alcançado pelo carvão CV. As capacidades adsortivas encontradas para o carvão CB foram de $125 \mathrm{mg}$ fenol. $\mathrm{g}^{-1}$ e $76 \mathrm{mg}$ BPA.g ${ }^{-1}$, enquanto que para o carvão CV foram $99 \mathrm{mg}$ fenol. $\mathrm{g}^{-1}$ e $27 \mathrm{mg} \mathrm{BPA} \cdot \mathrm{g}^{-1}$. Esses resultados estão associados à maior presença de grupos ácidos no carvão CV e à hidrofobicidade do BPA, o que torna o processo de adsorção desfavorável.

Palavras-chave: efluentes industriais, isotermas de adsorção, micropoluentes.

\section{Evaluation of Phenol and Bisphenol A (BPA) adsorption in commercial activated carbon from different carbonaceous matrices}

\section{ABSTRACT}

The removal of toxic organic compounds and organic micro-pollutants from industrial wastewater is a current and growing concern to improve water quality for reuse. To improve water quality, some treatments have been shown to be effective, such as the activated carbon 
adsorption treatment. This study evaluated the adsorption of phenol and bisphenol A (BPA) onto activated carbon from two different carbonaceous matrices: bituminous (CB) and vegetable $(\mathrm{CV})$. The activated carbons were characterized by scanning electron microscopy (SEM) equipped with an energy dispersive spectrometer (EDS), Fourier-transformed infrared spectroscopy (FTIR) and BET (Brunauer, Emmett, Teller) surface area. Assays were performed to determine equilibrium time and adsorption isotherms (Freundlich and Langmuir). Adsorption onto the two types of carbons favored phenol removal, resulting in $96 \%$ for the CB carbon and $91 \%$ of phenol removal for CV carbon. However, the adsorption of bisphenol A was efficient only for the CB carbon, resulting in $90 \%$ and $20 \%$ of BPA removal for $\mathrm{CB}$ and $\mathrm{CV}$, respectively. The adsorptive capacities determined for $\mathrm{CB}$ carbon were $125 \mathrm{mg}$ phenol. $\mathrm{g}^{-1}$ and $76 \mathrm{mg}$ BPA.g $\mathrm{g}^{-1}$, and for $\mathrm{CV}$ carbon were $99 \mathrm{mg}$ phenol. $\mathrm{g}^{-1}$ and 27 mg BPA. $\mathrm{g}^{-1}$. The results are related to the presence of acid groups in CV carbon and to the hydrophobicity of BPA, which makes the adsorption process unfavorable.

Keywords: adsorption isotherms, industrial wastewaters, micro pollutants.

\section{INTRODUÇÃO}

As indústrias de petróleo e químicas são as principais responsáveis por produzir uma grande variedade de compostos orgânicos poluentes que possuem elevada toxicidade, onde seu comportamento no meio ambiente causa sérios danos à saúde humana. Os poluentes orgânicos presentes nestes efluentes industriais, em geral, costumam ser resistentes à degradação natural, persistindo no ambiente. Muitos destes compostos possuem propriedades carcinogênicas, teratogênicas ou mutagênicas. Wake (2005) cita que os efluentes de refinaria de petróleo possuem alto teor de aromáticos policíclicos, que são tóxicos e corroboram com a ideia de compostos refratários presente nos efluentes.

A preocupação com a poluição por compostos aromáticos tais como fenóis, bisfenóis, aromáticos polinucleares entre outros, vem crescendo em níveis internacionais, pois atinge solos, águas superficiais e subterrâneas. Para os poluentes orgânicos resistentes à degradação natural, os processos citados visam a um pré-tratamento para torná-los biodegradáveis ou de menor toxicidade ao meio.

As tecnologias de tratamento de águas residuárias possuem como meta principal gerar efluentes tratados com qualidade relativa ao objetivo final. De acordo com Sant'Anna Jr. (2010), o conhecimento científico e as tecnologias disponíveis presentes em cada época ditavam o padrão de efluente possível de ser alcançado. Assim, além da remoção dos macropoluentes, há atualmente a preocupação com a remoção dos micropoluentes que estão presentes em baixíssimas concentrações nas águas residuárias, denominados também de poluentes emergentes.

Os micropoluentes bastante investigados são os fármacos, os poluentes orgânicos persistentes e os desreguladores endócrinos (presentes em $\mu \mathrm{g} \mathrm{L}^{-1}$ e $\mathrm{ng} \mathrm{L}^{-1}$ ) devido aos seus efeitos de médio e longo prazo causado à saúde humana e ao ambiente (Dezotti e Bila, 2007). Além dos efeitos causados pela formação de intermediários da degradação destes poluentes, que podem possuir propriedades químicas letais, como por exemplo, o bisfenol A (BPA). O Bisfenol A é considerado um interferente endócrino por diversas organizações de saúde mundiais, dentre elas estão a UKEA (Agência Ambiental do Reino Unido, USEPA (Agência de Proteção Ambiental dos Estados Unidos), JEA (Agência Ambiental do Japão), WWF (Organização não Governamental) (Ghiselli e Jardim, 2007).

O BPA tem apresentado vários efeitos deletérios e ainda há muito a se esclarecer sobre a exposição precoce do BPA aos seres humanos, como a diminuição na produção de esperma nos homens, como a estimulação de liberação de prolactina e a proliferação de 
células em câncer de mama nas mulheres; o aumento da má formação nos aparelhos reprodutivos feminino e masculino; como o fenômeno de maturação precoce em garotas e outras perturbações genéticas (Tsutsumi, 2005; Krotz et al., 2012 apud Montagner, 2003).

Considerando a possibilidade de recirculação e reúso do efluente industrial, muitos processos de tratamento vêm sendo estudados e aplicados, tais como os processos fotoquímicos, processos de adsorção em carvão ativado, processos de separação por membranas, além da combinação destes processos citados com a finalidade de obter alta qualidade para os efluentes tratados.

A adsorção em carvão ativado possui diversas finalidades, principalmente para purificação de águas e tratamento de efluentes que conferem cor, odor e sabor. Esta propriedade está relacionada ao fenômeno de adsorção que ocorre com determinados materiais que possuem porosidade, chamado de adsorvente, na presença de substâncias que se acumulam nesta superfície, conhecidas como adsorvato.

Adsorção é um termo utilizado em geral, para identificar o fenômeno físico ou químico que ocorre quando há diferença de concentração entre os componentes presentes no seio da fase fluida e os compostos em um sólido poroso (adsorvente) (Ciola, 1981). Os carvões ativados podem ser utilizados na forma granular ou pulverizados, em colunas de filtração, adicionados diretamente a sistemas biológicos ou como pré-tratamento (Machado, 2010). As características físico-químicas (área disponível para adsorção, grupos funcionais de superfície, porosidade) dos adsorventes que promovem a eficiência da adsorção relacionam-se com a matriz carbonácea utilizada na preparação destes materiais (Tsai et al., 2006).

Este estudo visa a investigação da adsorção de compostos orgânicos tóxicos ao ambiente, tais como fenol e bisfenol A (BPA), utilizando carvões ativados comerciais de diferentes matrizes carbonáceas.

\section{MATERIAIS E MÉTODOS}

\subsection{Soluções sintéticas utilizadas}

Os experimentos foram realizados com soluções sintéticas de fenol e bisfenol A e água deionizada. A concentração da solução de fenol utilizada foi de $100 \mathrm{mg} \mathrm{L}^{-1}$ e a solução de bisfenol A foi em torno de $20 \mathrm{mg} \mathrm{L}^{-1}$. Os reagentes utilizados foram fornecidos por Sigma Aldrich com 99,5\% de pureza (padrão para cromatografia gasosa). Cabe ressaltar que o fenol foi escolhido como adsorvato por ter sua adsorção conhecida e estudada funcionando, assim, como referência neste estudo. O bisfenol A (BPA) foi escolhido por ser um poluente persistente, estando presente em águas tratadas. Considerado como desregulador endócrino, o BPA em pequenas concentrações vem causando efeitos nocivos à saúde humana.

As condições experimentais aplicadas ao fenol e bisfenol A devem-se à reprodução de quantidades encontradas nas águas residuárias. Assim, o BPA é encontrado em concentrações bem menores do que o fenol. Portanto, as concentrações dos carvões também foram ajustadas.

\subsection{Caracterizações dos Carvões}

Os adsorventes utilizados foram os seguintes carvões ativados granulares: o carvão $\mathbf{C V}$, de origem vegetal, da marca Carbomafra C119 e de fabricação nacional e o carvão CB, de origem betuminosa, da marca Norit $1240 \mathrm{~W}$ e de fabricação estrangeira. Foram realizadas as seguintes análises de caracterização para os carvões:

- Área superficial BET - Na obtenção das isotermas de adsorção e dessorção de nitrogênio a 77 K utilizou-se um aparelho TriStar 3000 V6.07 A Surface Area and Pore Size Analyzer. As amostras foram pré-tratadas a $300^{\circ} \mathrm{C}$ por $12 \mathrm{~h}$, sob vácuo. A partir destas isotermas, a área superficial específica foi calculada pelo método BET, enquanto o volume e a distribuição de tamanho de poros foram determinados pelo método BJH. Esta análise foi 
realizada no Laboratório GREENTEC, na Escola de Química da UFRJ.

- Microscopia Eletrônica de Varredura (MEV) e Espectro de Energia Dispersiva (EDS) - Microscópio eletrônico de varredura JEOL 6460 LV, acoplado a um EDS Noran System Six, operados a baixo vácuo e sob 20 kV, realizada no Laboratório de Microscopia e Microanálises, da COPPE/UFRJ.

- Espectroscopia Infravermelho por Transformada de Fourrier (FTIR) - Equipamento Nicolet 6700-FTIR, com adição de pastilha de $\mathrm{KBr}$ ao material adsorvente e utilizando a faixa entre 4000 e $400 \mathrm{~cm}^{-1}$, realizada no Laboratório de Instrumentos e Pesquisa do Departamento de Química Inorgânica do Instituto de Química da UFRJ.

- Potencial Zeta - As medições de potencial zeta das partículas coloidais foram realizadas em um equipamento Zetasizer Nano(Nano-ZS) acoplado a um titulador multiuso (MPT-2), ambos do fabricante Malver. As medições foram realizadas para diferentes valores de $\mathrm{pH}$, visando a obtenção do $\mathrm{pH}$ que a carga da partícula apresenta o Ponto Iso-Elétrico (PIE). Na determinação do potencial zeta das partículas, empregou-se como eletrólito indiferente uma solução de $0,01 \mathrm{mmol} \mathrm{L}^{-1}$ de $\mathrm{KCl}$ preparada com água deionizada. A suspensão coloidal em água foi preparada na concentração de $0,5 \% \mathrm{~m} / \mathrm{V}$. Foram feitas soluções independentes de $0,1 \mathrm{~mol} \mathrm{~L}^{-1}$ de $\mathrm{HCl}$ e de $0,01 \mathrm{~mol} \mathrm{~L}^{-1}$ de $\mathrm{NaOH}$ para ajuste de $\mathrm{pH}$ pelo titulador automático.

\subsection{Experimentos realizados de adsorção}

\subsubsection{Avaliação do tempo de equilíbrio de adsorção para ambos os carvões}

Para os ensaios com Fenol foram utilizadas as concentrações dos carvões de $2 \mathrm{~g} \mathrm{~L}^{-1} \mathrm{e}$ soluções sintéticas de $100 \mathrm{mg} \mathrm{L}^{-1}$. Os ensaios com Bisfenol A (BPA) foram utilizadas as concentrações dos carvões de $0,5 \mathrm{~g} \mathrm{~L}^{-1}$ e soluções sintéticas de $20 \mathrm{mg} \mathrm{L}^{-1}$.

As condições experimentais aplicadas ao fenol e bisfenol A devem-se à reprodução de quantidades encontradas nas águas residuárias. Assim, o BPA é encontrado em concentrações bem menores do que o fenol. Portanto, as concentrações dos carvões também foram ajustadas.

\subsubsection{Levantamento de dados para o ajuste em isotermas}

Este ensaio foi realizado a partir do tempo de equilíbrio obtido no experimento anterior. As concentrações dos carvões utilizadas para o levantamento de dados para ambos os carvões foram 0,$5 ; 1,0 ; 2,0$ e $4,0 \mathrm{~g} \mathrm{~L}^{-1}$.

Os experimentos foram realizados com volume de $50 \mathrm{~mL}$ e rotação $240 \mathrm{rpm}$ a $25^{\circ} \mathrm{C}$. Os modelos de adsorção utilizados para os ajustes foram o de Freundlich (Equação1), que é largamente utilizado para estudos de adsorção associados ao tratamento e controle de poluentes, devido à maior possibilidade de ajuste ao modelo (Eckenfelder, 1999).

$$
q_{e}=K f C_{e}^{1 / n}
$$

em que:

qe: é expressa em unidade de massa de adsorvato/massa de adsorvente, ou moles de adsorvato/massa de adsorvente,

$C e$ : é expresso em unidade de massa/volume e,

$K \mathrm{f}$ e $n$ : são constantes experimentais.

O Modelo de Langmuir (Equação 2), considera que a adsorção ocorre em superfície homogênea, na qual a energia envolvida durante a acumulação em cada sítio seria igual (Ciola,1981). 


$$
q_{e}=\frac{q m a ́ x . b C_{e}}{1+b \cdot C_{e}}
$$

em que:

qmáx. corresponde à concentração de uma camada única de recobrimento do adsorvente pelo adsorvato e representa o valor máximo de qe,

$b$ : é a constante de Langmuir, sendo esta uma medida direta da intensidade de adsorção e, por isso, é também denominada constante de afinidade (Guilarduci et al, 2006).

$\mathrm{O}$ modelo de Langmuir pode também ser caracterizado pelo fator adimensional $\mathrm{R}_{\mathrm{L}}$ (Equação 3), que indica a forma da isoterma.

$$
R_{L}=\frac{1}{1+b \cdot C_{0}}
$$

em que:

$\mathrm{R}_{\iota}>1$ indicam que o processo é desfavorável,

$\mathrm{R}_{\mathrm{t}}=1$ indica uma isoterma linear,

$0<\mathrm{R}_{\llcorner}<1$ indica que o processo é favorável e

$\mathrm{R}_{\mathrm{t}}=0$ indica que o processo é irreversível (Dotto et al., 2011).

\subsection{Determinações analíticas}

Após cada experimento, a concentração de fenol foi medida utilizando-se o método fotométrico direto da 4-aminoantipirina, de acordo com o Standard Methods (5530D) (APHA et al., 2005). O bisfenol A foi analisado pela técnica de cromatografia líquida de alta eficiência, com detecção UV a partir do equipamento HPLC Autosampler 2707 (Waters PAH C18, $250 \mathrm{~mm}$ x 4.6, 186001265) e detector Photodiodo Array Detector 2998 (Water Technologies). O método de análise constitui-se de uma mistura de água ultra pura e acetonitrila (30:70) usada como fase móvel em modo isocrático (razão de fluxo: 1,0 mL min ${ }^{-1}$; volume de injeção $50 \mu \mathrm{L}$ ). A absorbância foi medida em $223 \mathrm{~nm}$. A curva de calibração foi realizada com sete pontos de concentração e $\mathrm{R}^{2}=0,9989$.

\section{RESULTADOS E DISCUSSÃO}

\subsection{Caracterização dos carvões}

\subsubsection{Análise Área BET}

Com base no método BET foi possível calcular a área superficial disponível para adsorção, assim como o volume e área dos microporos presentes no material adsorvente.

A Tabela 1 apresenta os resultados de porosidade e área superficial caracterizados pelo método BET para os carvões ativados granulares $\mathrm{CB}$ e para o carvão $\mathrm{CV}$. Os resultados obtidos para área superficial BET mostram que há uma diferença significativa nas áreas disponíveis para adsorção dos dois carvões. O carvão $\mathrm{CB}$ possui maior área $\mathrm{BET}$ do que o carvão CV.

Os resultados mostram que, de acordo com a classificação da IUPAC - União Internacional de Química Pura e Aplicada, o carvão CV é classificado como microporoso, por apresentar poros com diâmetro do menor que $20 \AA$, enquanto que o carvão CB é mesoporoso por apresentar poros com diâmetros entre 20 e $500 \AA$ (Gregg e Sing, 1982). 
Tabela 1. Resultados de área superficial e porosidade dos carvões CB e CV.

\begin{tabular}{llcc}
\hline \multicolumn{2}{c}{ Parâmetros de caracterização } & Carvão CB & Carvão CV \\
\hline \multirow{2}{*}{ Área Superficial } & Área BET & $971,8 \mathrm{~m}^{2} \mathrm{~g}^{-1}$ & $634,5 \mathrm{~m}^{2} \mathrm{~g}^{-1}$ \\
& Área microporo & $423,9 \mathrm{~m}^{2} \mathrm{~g}^{-1}$ & $546,4 \mathrm{~m}^{2} \mathrm{~g}^{-1}$ \\
Área externa & $547,9 \mathrm{~m}^{2} \mathrm{~g}^{-1}$ & $88,1 \mathrm{~m}^{2} \mathrm{~g}^{-1}$ \\
Tamanho de Poro & $\begin{array}{l}\text { Tamanho médio do } \\
\text { microporo }\end{array}$ & $22 \AA$ & $20 \AA$ \\
Volume do poro & $\begin{array}{l}\text { Volume médio do } \\
\text { microporo }\end{array}$ & $0,20 \mathrm{~cm}^{3} \mathrm{~g}^{-1}$ & $0,25 \mathrm{~cm}^{3} \mathrm{~g}^{-1}$ \\
\hline
\end{tabular}

A influência destes resultados de porosidade, adicionados a outros fatores investigados, pode ser observada nos testes de adsorção utilizando os poluentes orgânicos. $\mathrm{O}$ carvão $\mathrm{CB}$ provavelmente possui característica de mesoporosidade, enquanto que o carvão $\mathrm{CV}$ apresentaria características microporosas, embora os valores médios para o tamanho dos poros encontrados serem muito próximos.

\subsubsection{Microscopia Eletrônica de Varredura (MEV)}

As Figuras 1 (a) e (b) representam as fotomicrografias obtidas a partir da análise de microscopia eletrônica para os carvões virgem CB e CV, respectivamente.

(a)

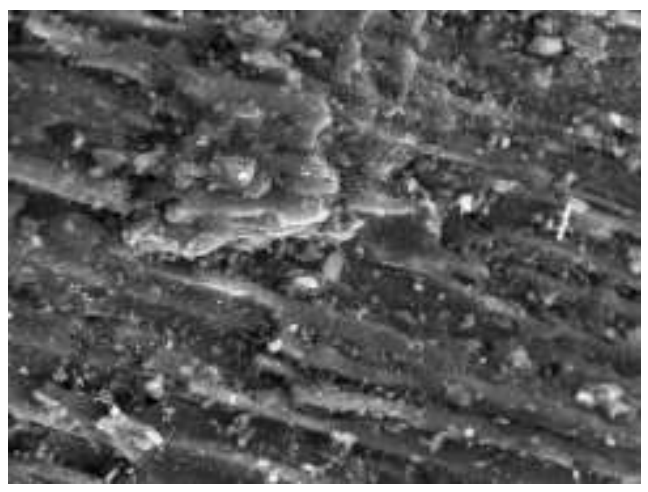

(b)

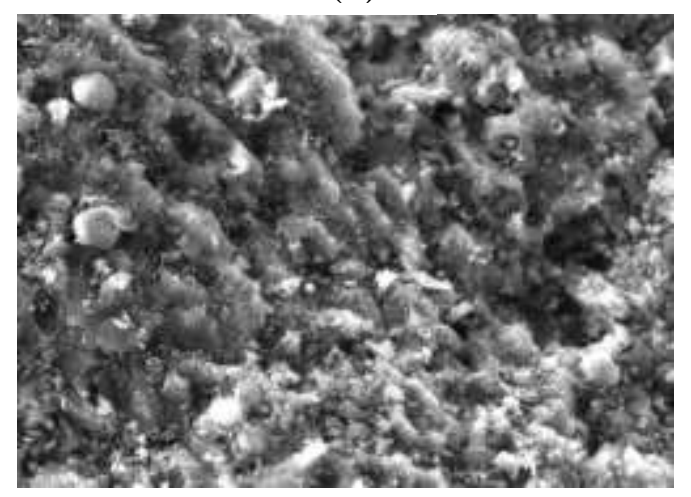

(a) Carvão CB com aumento de 700x;

Figura 1. Fotomicrografia das partícu
(b) carvão CV com aumento de 700x.

Pela análise das fotomicrografias foi possível observar que as partículas do carvão ativado granular $\mathrm{CB}$, avaliadas no microscópio, apresentam uma superfície heterogênea, dividida em partes lisas e outras rugosas. Enquanto que na análise do $\mathrm{CV}$, foi possível observar superfície rugosa, apresentando ranhuras resultantes de poros superficiais na maior parte de sua extensão.

Essas características estruturais encontradas estão relacionadas diretamente com a matriz que originou o carvão ativado (Machado, 2010).

$\mathrm{Na}$ análise complementar, utilizando o espectro de energia dispersiva (EDS), foram observados picos de baixa intensidade de alguns metais ( $\mathrm{Fe}, \mathrm{Al}, \mathrm{Si}, \mathrm{Ca}$ ) para o carvão $\mathrm{CB}$. No entanto, para o carvão $\mathrm{CV}$, foi observado apenas um pico de baixa intensidade indicando a presença de sílica. Assim, foi possível verificar que o carvão CV apresenta maior pureza que o carvão CB. 


\subsubsection{Análise de Espectroscopia no Infravermelho}

No espectro do infravermelho, foi possível identificar importantes regiões características de materiais adsorventes carbonáceos. Em ambos os carvões é possível observar uma banda larga na faixa entre 3400-3500 $\mathrm{cm}^{-1}$, caracterizando estiramento de ligação $\mathrm{O}-\mathrm{H}$ de grupos fenólicos ou ácidos carboxílicos (Silverstein e Bassler, 2006). Em ambos os espectros não é observada a presença da banda característica de carbonila, que normalmente apresenta-se em torno de $1700 \mathrm{~cm}^{-1}$, com forte intensidade.

No entanto, no carvão CV é observada a banda ilustrada em $1634 \mathrm{~cm}^{-1}$, atribuída às vibrações $\mathrm{C}=\mathrm{O}$ dos carboxilatos, provenientes da matéria orgânica (Pimentel et al., 2006), podendo indicar também a presença de ácidos, anidridos e lactonas, muito comuns em carvões ativados. Bandas entre 1570-1580 $\mathrm{cm}^{-1}$ e $1100 \mathrm{~cm}^{-1}$ aparecem nos espectros dos dois carvões, caracterizando a presença de ligação $\mathrm{C}=\mathrm{C}$ de aromáticos e a vibração da ligação $\mathrm{C}-\mathrm{O}$ de éteres ou álcoois, respectivamente (Guilarduci et al., 2006). Bandas específicas correspondentes ao carvão $\mathrm{CB}$, de origem betuminosa, aparecem em torno de $1460 \mathrm{~cm}^{-1} \mathrm{e}$ $875 \mathrm{~cm}^{-1}$, ilustrando a presença de grupos metilenos e a deformação da ligação $\mathrm{C}-\mathrm{H}$ fora do plano (Silverstein e Bassler, 2006), respectivamente. Uma banda em torno de $476 \mathrm{~cm}^{-1}$ foi observada apenas no carvão $\mathrm{CV}$, indicando presença de $\mathrm{SiO}_{2}$, como mostrado na análise de EDS. Portanto, infere-se que o carvão CV possui maior característica ácida em comparação ao carvão CB.

\subsubsection{Potencial Zeta}

A Figura 2 abaixo mostra a análise do comportamento de cargas na superfície dos materiais adsorventes utilizados. O carvão CV apresenta dois pontos isoelétricos (PIEs): um em pH 7,11 e outro em pH 10,2. Então, a partir da figura, verifica- se que abaixo de 7,11 e acima de 10,2, o carvão possui cargas negativas na sua superfície. Enquanto na faixa entre os PIEs a superfície possui cargas positivas. $\mathrm{O}$ carvão $\mathrm{CB}$ apresenta cargas positivas na sua superfície em $\mathrm{pH}<2,72$, o qual é o seu único ponto isoelétrico. Então, de acordo com a curva obtida, em valores de $\mathrm{pH}$ acima de 2,72; o carvão CV possui concentração de carga negativas na sua superfície.

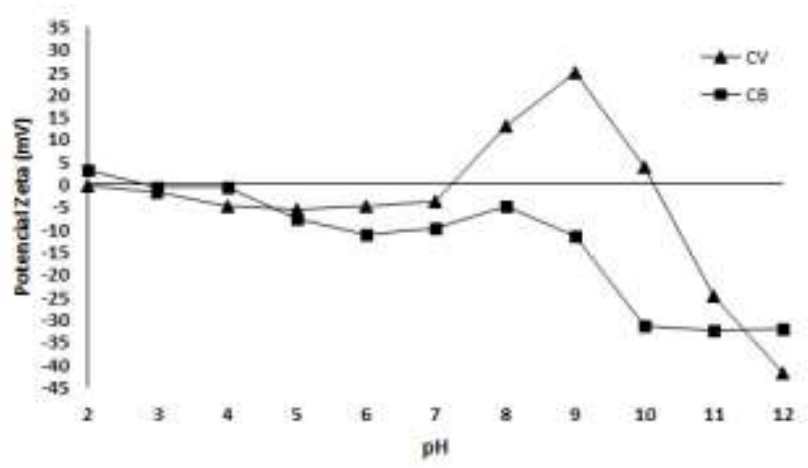

Figura 2. Análise do ponto de carga zero para os carvões CV e CB.

As soluções de fenol e bisfenol A utilizadas nos ensaios de adsorção possuem valores de $\mathrm{pH}$ em torno de 6,0 e 6,2, respectivamente. Assim, como os valores de pH das soluções são menores que seus valores de $\mathrm{pKa}$, as espécies mantêm-se no meio em suas formas neutras (Srivastava et al., 2005). Então, nestes valores de pH, ambos os carvões apresentam cargas negativas nas suas superfícies, o que diferenciaria pouco a adsorção destes compostos. A partir destes resultados, é possível inferir que as cargas presentes na superfície do carvão podem não influenciar de forma tão significativa a adsorção. 


\subsection{Ensaios de Adsorção}

\subsubsection{Tempo de Equilíbrio}

A Figura 3 abaixo ilustra os resultados obtidos nos ensaios realizados com os dois carvões, a fim de encontrar o tempo de equilíbrio da adsorção dos compostos fenol e bisfenol A (BPA).

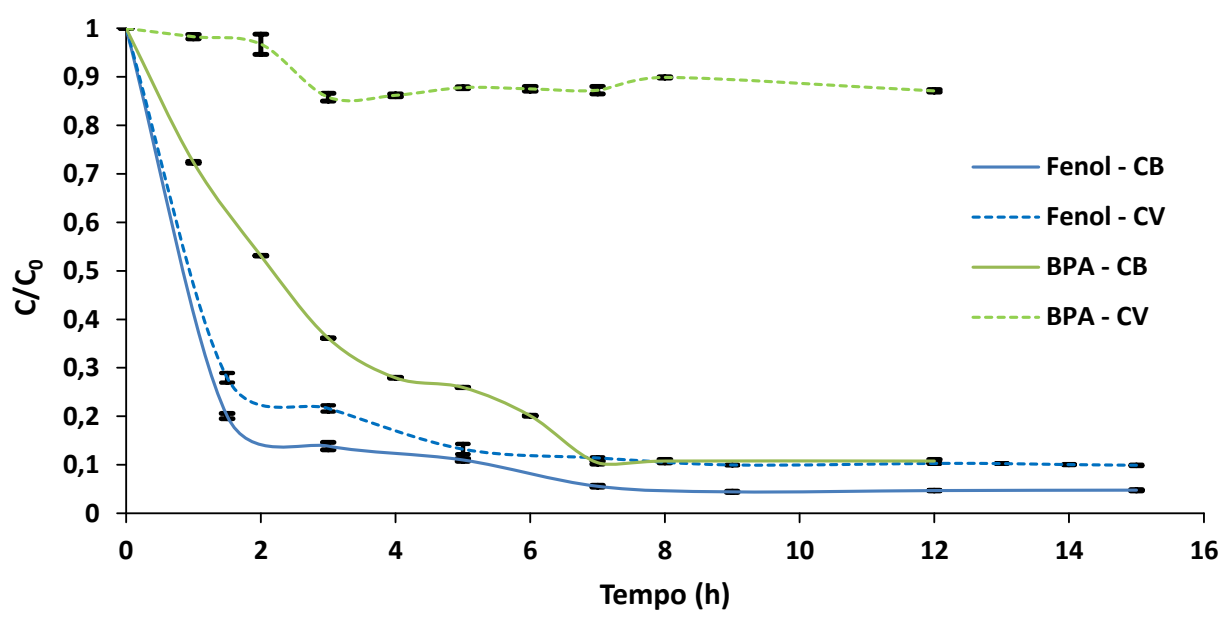

Figura 3. Avaliação do tempo de equilíbrio de adsorção com carvão CB e carvão CV em contato com fenol (Carvão $=2 \mathrm{~g} \mathrm{~L}^{-1}$ e Fenol $\left.=100 \mathrm{mg} \mathrm{L}^{-1}\right) \mathrm{e}$ Bisfenol A (Carvão $=20 \mathrm{mg} \mathrm{L}^{-1}$ e BPA $\left.=20 \mathrm{mg} \mathrm{L}^{-1}\right)$.

Os resultados mostraram que o tempo de equilíbrio obtido foi em torno de 8 horas para CB, alcançando adsorção de $96 \%$ de fenol. Para o carvão CV, o tempo de equilíbrio da adsorção foi em torno de 12 horas, com $91 \%$ de remoção de fenol.

Para o BPA, os resultados mostraram que o tempo de equilíbrio obtido foi em torno de 8 horas para o carvão $\mathrm{CB}$, com adsorção de $90 \%$ do bisfenol A. Para o carvão CV, o tempo de equilíbrio da adsorção foi em torno de 4 horas, com adsorção em torno de $20 \%$ da concentração inicial de bisfenol A.

A partir destes resultados, foi possível observar que a adsorção de bisfenol A no carvão $\mathrm{CV}$, de origem vegetal, foi menos favorável do que no carvão de origem betuminosa. Relacionando essas observações com a análise de área BET, é possível observar que, embora os tamanhos dos poros de ambos os carvões sejam muito próximos, o carvão CV possui características de menor porosidade e, assim, a adsorção do bisfenol é dificultada por seu maior tamanho quando comparado com o fenol.

Aktas e Çeçen (2007), em seus estudos sobre adsorção, dessorção e biorregeneração no tratamento de solução contendo 2-clorofenol com carvão ativado, relatam que a capacidade de adsorção tem relação com os grupos ácidos presentes na superfície do carvão. Assim, segundo os autores, quando houve menor presença de grupos ácidos no carvão, o que ocorre quando o carvão é ativado termicamente, a adsorção do 2-clorofenol foi maior. No presente trabalho, este comportamento foi também observado na baixa adsorção de bisfenol A no carvão CV, pois, de acordo com a análise de FTIR, este adsorvente apresenta grupo ácido específico $\left(1634 \mathrm{~cm}^{-1}\right)$, o que pode torná-lo mais ácido que o carvão CB.

\subsubsection{Isotermas de adsorção}

A Figura 4 ilustra as isotermas de adsorção plotadas considerando os pontos experimentais e o ajuste aos modelos de Freundlich e Langmuir. 
(a)

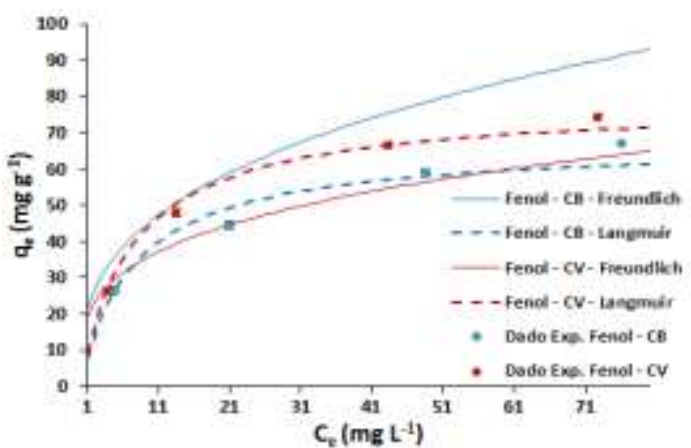

(b)

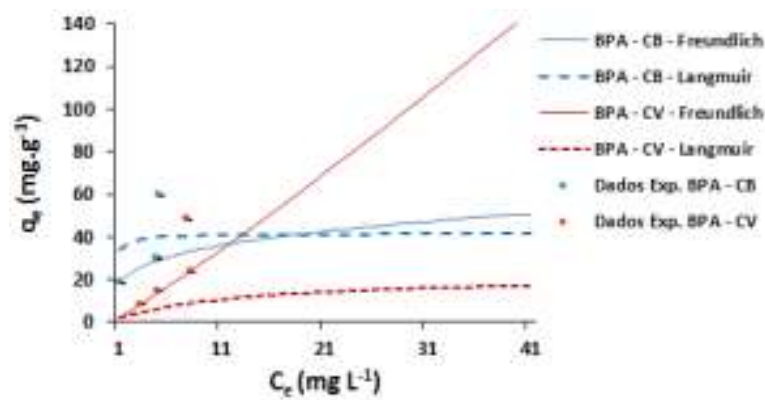

Figura 4. (a) Isotermas de Adsorção de fenol ajustadas aos Modelos de Freundlich e Langmuir para os carvões $\mathrm{CB}$ e CV (Carvão=2 $\mathrm{g} \mathrm{L}^{-1}$ e Fenol $=100 \mathrm{mg} \mathrm{L}^{-1}$ ); b) Isotermas de adsorção de bisfenol A (BPA) ajustadas aos Modelos de Freundlich e Langmuir para os carvões CB e CV. (Carvão=0,5 $\mathrm{g} \mathrm{L}^{-1}$ e BPA=20 $\mathrm{mg} \mathrm{L}^{-1}$ ).

A Tabela 2 apresenta os parâmetros experimentais obtidos no ajuste aos modelos de Freundlich e Langmuir para a adsorção com fenol e BPA. De acordo com a literatura, para o modelo de Freundlich, sabe-se que o parâmetro Kf indica a capacidade adsortiva para o carvão ativado e o valor de $1 / \mathrm{n}$ indica a força da ligação, assim quanto maior for o valor de $\mathrm{n}$, maior a irreversibilidade do processo indica que o valor de $n$ deve estar entre 2-10 para indicar uma adsorção favorável (Masschelein, 1992). Enquanto que o modelo de Langmuir considera que o primeiro estágio da adsorção seja a formação da monocamada, além de considerar que a adsorção pode ser um fenômeno químico. Embora esta teoria tenha limitações quanto à energia e as condições para formação da monocamada, foi considerado que como a solução em questão é monocomponente e assim, de menor complexidade, os parâmetros poderiam ser ajustados de forma satisfatória.

Tabela 2. Parâmetros obtidos nas isotermas dos carvões CB e CV com o fenol e bisfenol A ajustados aos Modelos de Freundlich e Langmuir.

\begin{tabular}{ccccccc}
\hline \multirow{2}{*}{ Modelos } & \multirow{2}{*}{ Parâmetros } & \multicolumn{2}{c}{ Carvão CB } & & \multicolumn{2}{c}{ Carvão CV } \\
\cline { 3 - 4 } \cline { 7 - 7 } Freundlich & $\mathrm{Kf}$ & 20,96 & 19,36 & & 19,03 & 2,42 \\
& $\mathrm{n}$ & 2,94 & 3,85 & & 3,57 & 0,91 \\
& $\mathrm{R}^{2}$ & 0,9999 & 0,9897 & & 0,9993 & 0,8153 \\
& $\mathrm{q}_{\text {máx. }}$ & 67,11 & 41,66 & & 78,11 & 22,02 \\
\multirow{2}{*}{ Langmuir } & $\mathrm{b}$ & 0,1317 & 4,6161 & & 0,1342 & 0,0868 \\
& $\mathrm{R}_{\mathrm{L}}$ & 0,06457 & 0,0109 & & 0,08709 & 0,3691 \\
& $\mathrm{R}^{2}$ & 0,9982 & 0,9985 & & 0,9961 & 0,9964 \\
\hline
\end{tabular}

Unidades: *Kf $\left(\mathrm{mg} \cdot \mathrm{g}^{-1}\right)\left(\mathrm{mg} \cdot \mathrm{L}^{-1) 1 / n} ; \mathrm{q}_{\text {máx }} \cdot\left(\mathrm{mg} \cdot \mathrm{g}^{-1}\right) ; \mathrm{b}\left(\mathrm{L} \cdot \mathrm{mg}^{-1}\right)\right.$.

Durante os ensaios de isoterma, verificou-se que a adsorção de fenol mostrou-se favorável, pois foram obtidos para o modelo de Freundlich e Langmuir os valores de $\mathrm{n}$ iguais a 2,94 e 3,57 e valores de qmáximo (capacidade máxima de adsorção de uma monocamada) de 67,11 e 78,11 $\mathrm{mg} \mathrm{g}^{-1}$ para CB e CV, para os carvões $\mathrm{CB}$ e CV, respectivamente.

Valores de $1 / \mathrm{n}$ próximos aos encontrados neste estudo foram verificados em estudos de adsorção de fenol com carvões ativados granulares e pulverizados oriundos de modos de ativação diferentes. Aktas e Çeçen (2006) encontraram valores de n correspondente a 5,35 e 
4,36 para adsorção de fenol em carvões ativados termicamente e quimicamente, respectivamente. Dobbs e Cohen (1980) investigaram a adsorção de compostos fenólicos em carvão ativado comercial Filtrasorb 300 (Calgon Corporation), assim encontraram valor de $\mathrm{Kf}$ $21 \mathrm{mg} \mathrm{g}^{-1}$ para adsorção de fenol aproximadamente e $\mathrm{n}$ de 1,85. Enquanto que para a adsorção de 2-clorofenol, obtiveram Kf correspondente a $51 \mathrm{mg} \mathrm{g}^{-1}$ e $\mathrm{n}$ igual a 2,43.

O resultado da adsorção de bisfenol A para o carvão CB ajustou-se de forma satisfatória ao modelo de Freundlich (Tabela 2), obtendo-se como parâmetros experimentais os valores de Kf igual a 19,36 e n de 3,85. Enquanto que o mesmo comportamento não foi observado na adsorção do composto no carvão $\mathrm{CV}$, obtendo-se para $\mathrm{Kf}$ e $\mathrm{n}$ os valores de 2,46 e 0,91, respectivamente. Verifica-se, então, que a adsorção de BPA em CV não é favorável, pois o valor de Kf resultou num valor muito baixo em relação ao carvão $\mathrm{CB}$ e o valor de $\mathrm{n}$ que se apresentou muito baixo, fora da faixa de entre 2-10 indicando a pouca interação entre adsorvente e adsorvato.

O comportamento da adsorção do bisfenol repetiu-se no ajuste ao modelo de Langmuir, pois a partir dos valores encontrados para o q máx. e para o parâmetro b, quando comparado os dois carvões, é possível verificar que a adsorção com o carvão CV possui menor intensidade do que com o carvão CB.

A teoria de Langmuir admite que a adsorção ocorre em sítios específicos e homogêneos na superfície do adsorvente, e cada sítio é responsável pela adsorção de apenas uma molécula de bisfenol A. Assim, a formação da monocamada para o carvão CV pode ter sido dificultada provavelmente devido a um impedimento estérico à formação das camadas posteriores na adsorção, pois a molécula de bisfenol A possui maior tamanho quando comparado ao fenol e este adsorvente possui tamanho de poro menor que o carvão $\mathrm{CB}$, que adsorveu melhor o bisfenol A.

Park et al. (2015) compararam a adsorção de bisfenol A em diferentes tipos de adsorventes, incluindo carvões ativados e minérios como hematita e magnesita. Então, verificou que o carvão que continha teores de íon ferro adsorveu maior quantidade do composto, através da formação de complexos de coordenação entre os grupos hidroxila e o ferro. De acordo com a análise de EDS para os carvões CB e CV, verifica-se também a presença de ferro em $\mathrm{CB}$, o que pode corroborar para maior adsorção de bisfenol.

A partir destes valores, é possível inferir que a adsorção de bisfenol não é preferencial quando comparada ao fenol, visto que o valor obtido para a formação da monocamada ( $\mathrm{q}_{\text {máx. }}$ ) está duas vezes menor do que valor encontrado para o fenol.

A adsorção de bisfenol A quando comparada à adsorção de fenol, considerando ambos os carvões, mostrou-se menos favorável. Adicionalmente, os resultados da adsorção de BPA no carvão CV apresentaram-se de forma menos satisfatória dentre todos os sistemas estudados. Os resultados encontrados referentes às baixas adsorções do carvão CV para o BPA podem estar relacionados às características químicas da superfície do carvão e porosidade dos adsorventes. Na análise de infravermelho, o carvão CV possui uma banda específica em 1643 $\mathrm{cm}^{-1}$ que trata-se de grupos carboxilatos, que podem deixar a superfície mais carregada negativamente em comparação ao carvão CB. E então, pode ocorrer repulsão eletrostática entre a superfície polar do adsorvente e a estrutura hidrofóbica do bisfenol A, já que seu coeficiente octanol-água $\left(\mathrm{K}_{\mathrm{ow}}\right)$ tem valor em torno de 3,4 que confere elevada hidrofobicidade ao composto (Choi et al., 2005). Esta observação também foi feita por Tsai et al. (2006), que estudaram a adsorção de bisfenol A em diferentes materiais adsorventes, tais como carvões ativados e minérios (andesita, terra diatomácea), além de comparar carvões de diferentes matrizes carbonáceas. Os autores verificaram que a baixa adsorção de bisfenol estava relacionada com o aumento da quantidade de grupos ácidos na superfície, o que ocorria para os minerais. Assim como neste estudo, eles também encontraram valores de área BET e qmáx. maiores para o carvão betuminoso quando comparado ao vegetal. 
No entanto, a análise do ponto isoelétrico mostrou que os adsorventes possuem, numa grande faixa de $\mathrm{pH}$, suas superfícies negativas. Então, a concentração de cargas na superfície do material pode não exercer grande influência no fenômeno da adsorção destes compostos nestes carvões. Assim, é necessário considerar, além da polaridade entre adsorvato e adsorvente, também as características de área superficial e porosa entre os carvões aqui estudados.

\section{CONCLUSÕES}

A partir dos resultados obtidos, pode-se concluir que:

- O carvão CB apresentou-se mais eficiente na adsorção de fenol, com 96\% de remoção em comparação ao carvão CV (91\%). O mesmo comportamento foi observado na remoção de bisfenol A, porém com maior diferença de remoção. Houve remoção de BPA de $90 \%$ e $20 \%$ para os carvões CB e CV, respectivamente.

- Os ajustes aos modelos de Freundlich e Langmuir foram realizados com sucesso para a adsorção de fenol, considerando ambos os carvões. A adsorção de bisfenol A também ajustou-se de forma satisfatória ao de Langmuir, considerando ambos os carvões. Para o modelo de Freundlich, apenas o carvão CB ajustou-se com sucesso.

- Os fatores observados que influenciam a adsorção podem estar relacionados com a área superficial disponível para adsorção, tamanho médio dos poros, característica da superfície do adsorvente (presença de grupos ácidos, metais), polaridade e tamanho da molécula do adsorvato.

- As características físico-químicas encontradas para os carvões ativados comerciais, tais como área superficial, densidade de carga na superfície etc. estão relacionadas diretamente com as matrizes carbonáceas - vegetal e betuminosa.

- Para remoção de fenol de águas, os dois carvões podem ser utilizados com sucesso, visto que o carvão CV possui menor custo devido a origem nacional. No entanto, para remoção de bisfenol $\mathrm{A}$, o carvão $\mathrm{CB}$ é mais eficiente, pois possui maior habilidade em reduzir a quantidade deste poluente, reduzindo futuros impactos ambientais.

\section{AGRADECIMENTOS}

Os autores agradecem à CAPES pela bolsa de doutorado e fomento ao estudo, ao Laboratório de Instrumentos e Pesquisa do Departamento de Química Inorgânica do Instituto de Química da UFRJ, ao Laboratório de Controle de Poluição de Águas e ao laboratório GREENTEC, na Universidade Federal do Rio de Janeiro e ao Laboratório de Engenharia Sanitária da Universidade do Estado do Rio de Janeiro, pelas análises realizadas.

\section{REFERÊNCIAS}

AKTAS, O.; ÇEÇEN, F. Effect of type of carbon activation on adsorption and its reversibility. Journal of Chemical Technology and Biotechnology, v. 81, p. 94-101, 2006. http://dx.doi.org/10.1002/jctb.1363

AKTAS, O.; ÇEÇEN, F. Adsorption, desorption and bioregeneration in the treatment of 2chlorophenol with activated carbon. Journal of Hazardous Materials, v. 141, p. 769777, 2007. http://dx.doi.org/10.1016/j.jhazmat.2006.07.050 
AMERICAN PUBLIC HEALT ASSOCIATION - APHA; AMERICAN WATER WORKS ASSOCIATION - AWWA; WATER ENVIRONMENT FEDERATION - WEF. Standard methods for the examination of water and wastewater. $21^{\text {th }} \mathrm{ed}$. Washington, 2005.

BRUNAUER, S.; EMMETT, P. H.; TELLER, E. Adsorption of gases in multimolecular layers. Journal of the American Chemical Society, v. 60, p. 309-319, 1938. http://dx.doi.org/10.1021/ja01269a023

CHOI, K. J.; KIM, S. G.; KIM, C. W.; KIM, S. H. Effects of activated carbono types and service life on removal of endocrine disrupting chemicals: amitrol, nonylphenol, and bisphenol-A. Chemosphere, v. 58, p. 1535-1545, 2005.

http://dx.doi.org/10.1016/j.chemosphere.2004.11.080

CIOLA, R. Fundamentos da Catálise. São Paulo: EdUSP, 1981.

DEZOTTI, M.; BILA, D. M. Desreguladores endócrinos no meio ambiente: efeitos e consequências. Química Nova, v. 3, n. 3, p. 651-666, 2007.

DOBBS, R. A.; COHEN, J. M. Carbon adsorption isotherm of toxics organics. EPA600/8-80-023. Washington: USEPA, 1980.

DOTTO, G. L.; VIEIRA, M. L. G.; GONÇAlVES, J. O.; PINTO, L. A. A. Remoção dos corantes azul brilhante, amarelo crepúsculo e amarelo tartrazina de soluções aquosas utilizando carvão ativado, terra ativada, terra diatomácea, quitina e quitosana: estudos de equilíbrio e termodinâmica. Química Nova, v. 34, n. 7, p. 1193-1199, 2011. http://dx.doi.org/10.1590/S0100-40422011000700017

ECKENFELDER, J. W. W. Industrial water pollution control. 3. ed. New York: Mc GrawHill, 1999. (Water Resources and Environmental Engineering).

GHISELLI, G.; JARDIM, W. F. Interferentes endócrinos no ambiente. Química Nova, v. 30, n. 3, p. 695-706, 2007. http://dx.doi.org/10.1590/S0100-40422007000300032

GUILARDUCI, V. V. S.; MESQUITA, J. P.; MARTELli, P. B.; GORGULHO, H. F. Adsorção de fenol sobre carvão ativado em meio alcalino. Química Nova, v. 29, n. 6, p. 1226-1232, 2006. http://dx.doi.org/10.1590/S0100-40422006000600015

GREGG, S. J.; SING, K. S. W. Adsorption, surface area and porosity. [S.1.]: Academic Press, 1982. p. 40-48.

MACHADO, C. R. A. Avaliação do processo de lodos ativados combinado com carvão ativado em pó no tratamento de efluente de refinaria de petróleo. 2010. Dissertação (Mestrado) - Escola de Química, Universidade Federal do Rio de Janeiro, 2010.

MASSCHELEIN, W. J. Adsorption. In: MARCEL DEKKER, INC. Unit processes in drinking water treatment. Nova York: [s.n.], 1992. p. 321-363.

MONTAGNER, T. A. Desenvolvimento e validação de método de análise de bisfenol A em amostras de saliva humana por cg-em. 2003. Dissertação (Mestrado) - Instituto de Química, Fundação Universidade Federal de Mato Grosso do Sul, Campo Grande, 2003. 
PARK, H.; KODURU, J. R.; CHOO, K.; LEE, B. Activated carbons impregnated with iron oxide nanoparticles forenhanced removal of bisphenol A and natural organic matter. Journal of Hazardous Materials, v. 286, p. 315-324, 2015. http://dx.doi.org/10.1016/j.jhazmat.2014.11.012

PIMENTEL, P. M.; SILVA JR., C. N.; MELO, D. M. A.; MALDONADO, G.; HENRIQUE, D. M. Caracterização e uso de xisto para adsorção de chumbo (II) em solução. Cerâmica, v. 52, p. 194-199, 2006. http://dx.doi.org/10.1590/S036669132006000300013

SANT'ANNA JÚNIOR, G. L. Tratamento biológico de efluentes: fundamentos e aplicações. Rio de Janeiro: Interciência, 2010.

SRIVASTAVA, V. C.; SWAMY, M. M.; MALL, I. D.; PRASAD, B.; MISHRA, I. M. Adsorptive removal of phenol by bagasse fly ash and activated carbon: Equilibrium, kinetics and thermodynamics. Colloids and Surfaces A: Physicochemical and Engineering Aspects, v. 272, p. 89-104, 2005. http://dx.doi.org/10.1016/j.colsurfa.2005.07.016

SILVERSTEIN, R. M.; BASSLER, G. C. Identificação espectrométrica de compostos orgânicos. 5. ed. Guanabara: LTC, 2006.

TSAI, W. T.; LAI, C. W.; SU, T. Adsorption of bisphenol-A from aqueous solution onto minerals and carbon adsorbents. Journal of Hazardous Materials, v. 134, p. 169-175, 2006. http://dx.doi.org/10.1016/j.jhazmat.2005.10.055

WAKE, H. Oil refineries: a review of their ecological impacts on the aquatic environment. Estuarine, Coastal and Shelf Science, v. 62, p. 131-140, 2005. http://dx.doi.org/10.1016/j.ecss.2004.08.013 